\title{
Doctoral Students' Perceived Barriers that Slow the Progress toward Completing a Doctoral Dissertation: A Mixed Analysis
}

\author{
Eunjin Hwang \\ Department of Educational Leadership and Counseling, Box 2119 \\ Sam Houston State University, Huntsville, Texas 77341-2119, USA \\ Tel: 1-936-444-8098_E-mail: eunjinhwang_education@yahoo.com \\ Rachel N. Smith \\ Department of Educational Leadership and Counseling, Box 2119 \\ Sam Houston State University, Huntsville, Texas 77341-2119, USA \\ Tel: 1-832-647-1099_E-mail: rachel_smith2012@yahoo.com \\ Valerie Tharp Byers \\ Department of Educational Leadership and Counseling, Box 2119 \\ Sam Houston State University, Huntsville, Texas 77341-2119, USA \\ Tel: 1-832-588-4126 E-mail: vtbyers@gmail.com
}

\section{Shirley Dickerson}

Department of Educational Leadership and Counseling, Box 2119

Sam Houston State University, Huntsville, Texas 77341-2119, USA

Tel: 1-936-553-7087_E-mail: shirley_dickerson@hotmail.com

\section{Leah McAlister-Shields}

Department of Educational Leadership and Counseling, Box 2119

Sam Houston State University, Huntsville, Texas 77341-2119, USA

Tel: 1-713-430-6593Ｅ-mail: leah.m.shields@gmail.com 
Anthony J. Onwuegbuzie (Corresponding author)

Department of Educational Leadership and Counseling, Box 2119

Sam Houston State University, Huntsville, Texas 77341-2119, USA

Tel: 1-936-294-4509Ｅ-mail: tonyonwuegbuzie@aol.com

\title{
Cindy Benge
}

Department of Educational Leadership and Counseling, Box 2119

Sam Houston State University, Huntsville, Texas 77341-2119, USA

Tel: 1-281-985-6401Ｅ-mail: clbenge@aldineisd.org

Received: May 30, 2015 Accepted: June 28, 2015 Published: June 30, 2015

doi:10.5296/jei.v1i1.7703 URL: http://dx.doi.org/10.5296/jei.v1i1.7703

\begin{abstract}
The non-completion of doctoral degrees has been a concern due to its economic, social, and personal consequences. In the current study, the researchers investigated perceived barriers of select doctoral students in completing their doctoral degrees by utilizing a fully mixed sequential mixed research design. The quantitative and qualitative data were concurrently collected using identical samples $(n=205)$ via a Reading Interest Survey questionnaire. A sequential mixed analysis revealed 6 emergent themes: external obligations (36\%), challenges to doctoral-level researchers (34\%), practical/logistical constraints $(23 \%)$, emotional concerns (15\%), program structure (9\%), and support for completion ( $8 \%)$. Also, 3 meta-themes were identified (i.e., dissociation, external/internal barriers, and institutional/personal barriers), which aided in explaining the relationships among the 6 primary themes. Implications of the findings are discussed.
\end{abstract}

Keywords: Doctoral students, Doctoral degree completion, Barriers of doctoral students, Mixed methods research, Mixed research, Mixed analysis

\section{Introduction}

Doctoral students are the most educationally advanced students in the higher education system; yet, paradoxically, this group is the least likely to achieve their main academic goal-doctoral degree completion (Golde, 2000). According to the Council of Graduate Schools (CGS, 2008), only $41 \%$ of students enrolled in doctoral programs in the United States successfully complete their degrees within a period of 7 years. Further, only $57 \%$ complete their degrees within a 10 -year time-frame. Moreover, $20 \%$ of doctoral candidates dropped out at the coursework completion stage, with only the dissertation remaining (Bowen 
\& Rudenstine, 1992).

The loss of doctoral students midway in the academic process has been a concern because the reduced retention of the highly educated individuals results in economic and intellectual drains in both universities and funding agencies (Bowen \& Rudenstine, 1992; McAlpine \& Norton, 2006). In addition to this economic and intellectual drain, doctoral student attrition has social and personal consequences (e.g., depleting intellectual competitiveness and devastating personal lives; Gardner, 2009). The loss of doctoral students who finish all but their dissertations is detrimental for the departments and universities because the total expense per student accumulates while each student is enrolled in coursework. In order to lower attrition rates and to facilitate completion rates of doctoral students, knowledge of constraining factors influencing doctoral students' degree completion is needed. Unfortunately, this information currently is lacking.

Given the paucity of information in the literature, the purpose of this study was to investigate possible barriers that doctoral students experience, especially when working towards completing their dissertations. We hoped that this investigation would be informative for faculty members or administrators in higher education in helping to promote doctoral programs by suggesting effective support mechanisms.

\subsection{Gender, Grade Point Average, and Doctoral Degree Completion}

A number of researchers have identified gender differences in quantitative outcomes - such as grade point average (GPA) in colleges - indicating that female undergraduate students tend to have higher GPAs than do their male counterparts (e.g., Chee, Pino, \& Smith, 2005). Similarly, findings from some previous studies have indicated that at the graduate level, female students have tended to outperform male students with equal or better GPA scores (Berg \& Ferber, 1983; Girves \& Wemmerus, 1988). However, research on the relationship between gender and GPA among doctoral students currently is lacking.

With respect to the relationship between academic factors and doctoral degree completion, Bair and Haworth (2005), who conducted a qualitative meta-synthesis of published research studies, concluded that academic achievement indicators such as GPA did not predict degree completion effectively. Consistent with Bair and Haworth (2005), Malone, Nelson, and Nelson (2004) reported that GPA had a minimal impact on doctoral completion, recommending that researchers focus on non-quantitative factors that determine the quality of doctoral programs in seeking knowledge on doctoral completion.

Likewise, gender has not been found to be a determinant of doctoral degree completion (Attiyeh, 1999; Malone et al., 2004). However, gender differences in the employment and career path during or after doctoral program have been identified (Malone et al., 2004). Malone et al. (2004) documented gender differences in the field of educational administration in terms of employment and career, indicating that male and female doctoral students bring different needs, aspirations, and expectations at the entry of their programs. Even though gender has not emerged as a statistically significant predictor of doctoral degree completion, many researchers have documented the unique challenges and barriers of female doctoral 
students in completing their doctoral programs (e.g., Maher, Ford, \& Thompson, 2004; Manfield, Welton, Lee, \& Young, 2010; Moyer, Salovey, \& Casey-Cannon, 1999). These challenges have included greater work demand, financial constraints, child-care responsibilities, and low level of confidence (Maher et al., 2004; Manfield et al., 2010; Moyer et al., 1999).

\subsection{Constraining Factors to Doctoral Student Completion}

Previous studies have shown that various factors influence degree completion (Lovitts, 2001). In particular, Smith, Maroney, Nelson, A. L. Abel, and H. S. Abel (2006) documented that both institutional and individual factors contribute to high rates of attrition. Institutional factors that have existed within the doctoral program include doctoral program structure, doctoral student adviser, and the lack of program flexibility. In contrast, individual factors include relationships and responsibilities within family and work life, other strains of finance, time, and overload and established support systems buffering all the challenges (Smith et al., 2006). Additionally, Golde (2005) identified inadequate academic integration as a significant factor influencing the attrition of doctoral students in association with Tinto's (1993) theory. Many researchers have attempted to investigate constraining factors to doctoral student departure; however, most of these studies have been solely quantitative or qualitative dominant in nature, and only a few researchers (e.g., Wao \& Onwuegbuzie, 2011) have utilized mixed research (i.e., mixed methods research) techniques. Thus, in the current study, we examined perceived barriers in completing doctoral programs by utilizing mixed analyses of both quantitative and qualitative data.

\section{Theoretical Framework}

Two theories were utilized as a theoretical framework for the study. First, Tinto's (1993) doctoral persistence theory was employed to explain the reasons that might impede doctoral students' degree completion. Tinto's (1993) doctoral persistence theory is derived from Tinto's (1975) Interactionist Model emphasizing the interaction within the academic environment to explain dropouts of undergraduate students. However, Tinto (1993) clarified the differences between undergraduate/master's students and doctoral students, which involve intensity of social and academic integration as well as a sense of belonging not only to departments/institutions but also to fields of study. To understand doctoral student persistence, Tinto (1993) conceptualized a theoretical model with three stages, transitional phase, leading to candidacy, and dissertation. Tinto (1993) postulated that doctoral students might have various challenges in each phase, but they can achieve their professional career attainments if they are persistent throughout the phases. Additionally, in attaining their professional careers, relationships with professors and peers are imperative, directly facilitating the academic and social integration of doctoral students (Tinto, 1993).

Second, Weidman, Twale, and Stein (2001)conceptualized a graduate socialization framework that highlighted relationships with individuals who provide support to doctoral students for their completions. Even though the relationship with faculty or advisors is central with respect to doctoral completion, personal communities (e.g., family, friends, and employers), who are not associated with academic programs but influence the graduate 


\section{Macrothink}

completion, also are included within the framework (Weidman et al., 2001). The graduate socialization process involves four stages (i.e., anticipatory, formal, informal, personal stage) that students undergo, and this process is nonlinear, dynamic, and ongoing (Weidman et al., 2001).

Taken together, both theoretical models for doctoral student persistence provide a framework for understanding various factors that might influence persistence and attrition of doctoral students. Figure 1 displays how these two theories combined provided a framework for this study. Tinto's (1993) doctoral theory of persistence explains the interaction between students and institutions throughout the stages of doctoral programs (i.e., coursework, candidacy, dissertation), whereas Weidman et al.'s (2001) graduate socialization framework illuminates a dynamic and fluid socialization process of doctoral students entangled with various components, including relationships within both professional communities and personal communities. Based on these theories, we explored possible challenges at the stage of degree completion within the academic program as well as other challenges outside of the academic program that might slow doctoral degree completion.

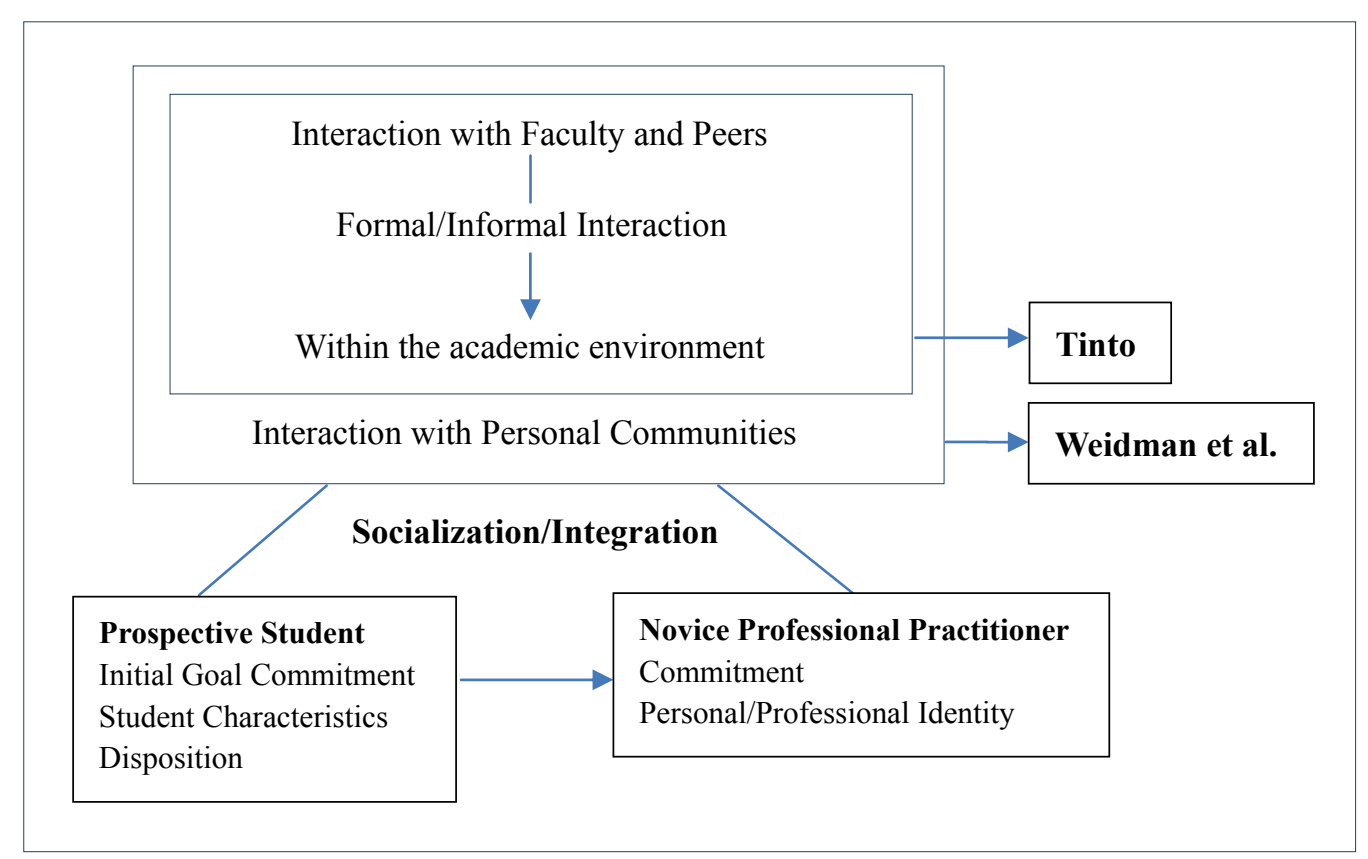

Figure 1. Theoretical framework for the current study

\section{Methodological Framework}

Collins, Onwuegbuzie, and Sutton's (2006) 13-step model was utilized as a methodological framework for the current mixed research study. These 13 steps, which are continuous and interactive, occur at three stages of the mixed research process (i.e., the Formulation Stage, the Planning Stage, and the Implementation Stage). Each step is highlighted in the following sections. 


\subsection{Mixed Goal (Step 1)}

Newman, Ridenour, Newman, and DeMarco's (2003) typology identified potential goals of a mixed research study. Their nine goals of research are (a) to predict; (b) to add to the knowledge base; (c) to have a personal, social, institutional, and/or organizational impact; (d) to understand complex phenomena; (e) to measure change; (f) to generate new ideas; ( $\mathrm{g}$ ) to test new ideas; (h) to inform constituencies; and (i) to examine the past. The goals of this current study were (a) to add to the knowledge base and (b) to have a personal, social, institutional, and/or organizational impact.

\subsection{Mixed Research Objectives (Step 2)}

According to Johnson and Christensen (2010), there are five major research objectives. These objectives are (a) exploration, (b) description, (c) explanation, (d) prediction, and (e) influence. For this study, the objective in the qualitative phase was to explore the perceived barriers of doctoral students' degree completion; the objective of the quantitative phase was to describe this phenomenon; with regard to the mixed research phase, the objective was to explain the relationships among the perceived barriers of doctoral students' degree completion.

\subsection{Rationale for Mixing (Step 3)}

Four rationales for conducting mixed research have been identified by Collins et al. (2006). These rationales are (a) participant enrichment, (b) instrument fidelity, (c) treatment integrity, and (d) significance enhancement. Our rationale for mixing quantitative and qualitative techniques was significance enhancement. Significance enhancement concerns utilizing qualitative and quantitative research techniques to enhance the interpretation of data. With respect to significance enhancement, both qualitative and quantitative data were collected via the questionnaire that contained open- and closed-ended items to maximize the interpretation of data (i.e., quantitative analyses were utilized to enhance qualitative analyses). For example, themes were generated from the qualitative responses, and, additionally, the relationship between these themes and quantitative variables (i.e., gender, GPA) were investigated. By mixing qualitative and quantitative data analyses, both sets of data expanded and confirmed what was learned from the other set, which enhanced the significance of the findings.

\subsection{Purpose for Mixing (Step 4)}

Using Greene, Caracelli, and Graham's (1989) typology, two purposes for mixing qualitative and quantitative research approaches were employed. These were (a) complementarity (i.e., utilizing both qualitative and quantitative techniques to measure a phenomenon from multiple aspects leading to richer data) and (b) expansion (i.e., increasing the scope of the study by utilizing different methods to evaluate the different components of the inquiry). The purposes of this study were (a) to explore the perceived barriers of doctoral students in completing their doctoral programs, (b) to examine the relationships among the perceived barriers, and (c) to examine the relationships between barriers and quantitative variables (gender, GPA). 


\subsection{Research Questions (Step 5)}

For the current study, combination research questions were used. According to Plano Clark and Badiee (2010), combination research questions represent at least one mixed research question combined with separate quantitative and qualitative research questions. In our study, the research questions were as follows:

Quantitative research question. For the quantitative phase of this study, the following research question was addressed:

(a) What is the relationship between gender and GPA of selected doctoral students?

Qualitative research question. For the qualitative phase of this study, the following research question was addressed:

(b) What are the perceived barriers that slow the progress toward completing a doctoral dissertation?

Mixed research questions. The following mixed research questions were addressed:

(c)What is the prevalence of each of the perceived barriers that slow the progress toward completing a doctoral dissertation?

(d) How do these perceived barriers that slow the progress of doctoral students in completing their dissertation relate to one another?

(e) What is the relationship between themes and quantitative variables (i.e., gender, GPA)?

\section{Method}

\subsection{Participants and Setting}

The participants $(n=205)$ were students enrolled in doctoral programs across 32 different majors within the College of Education at a large Tier I research university in the southeastern United States. These participants were enrolled in either a Ph.D. program $(n=$ $174,84.9 \%)$ or an Ed.D. $(n=31,15.1 \%)$ program. The majority of participants was female $(n$ $=123,60.0 \%)$, English speaking $(n=178,86.8 \%)$, and White $(n=130,64.3 \%)$. The remaining participants were American Indian or Alaskan Native $(n=30,14.9 \%)$, Hispanic or Latino $(n=18,8.9 \%)$, Black or African American $(n=14,6.9 \%)$, or Asian $(n=10,5.0 \%)$. Approximately $53.2 \%(n=109)$ of the doctoral students were working on a full-time basis. The mean GPA was $3.97(S D=2.60)$ on a 4-point scale.

\subsection{Sampling Design (Step 6)}

The 205 doctoral students were selected via a convenience sampling scheme (Johnson \& Christensen, 2010). Because a minimum sample size of 128 provided a statistical power of .80 for detecting a statistically significant and moderate (i.e., Cohen's [1988] $d=.50$ ) difference between two groups at the 5\% level of statistical significance (Faul, Erdfelder, Lang, \& Buchner, 2007), the sample size of 205 represented more than adequate statistical power for detecting this difference. A concurrent design using identical samples (Collins, Onwuegbuzie, 
\& Jiao, 2007; Onwuegbuzie \& Collins, 2007; Onwuegbuzie, Slate, Leech, \& Collins, 2007) was utilized as the mixing sampling design. Specifically, all 205 contributed data to both the qualitative and quantitative phases of the investigation that were collected concurrently.

\subsection{Research Design (Step 7)}

Using Leech and Onwuegbuzie's (2009) typology of mixed research designs, this study was determined to represent a fully mixed concurrent equal status design because (a) the qualitative and quantitative approaches were mixed within multiple stages of the research process, specifically, the data collection, data analysis, and data interpretation stages; (b) the initial quantitative and qualitative data were collected and analyzed concurrently, and (c) both phases were given nearly equal weight.

\subsection{Data Collection (Step 8)}

Instrument. The key instrument utilized for this study was a Reading Interest Survey (RIS). This instrument elicited background information (e.g., gender, age, native language, ethnicity, present major field of study, and degree pursuing). In addition, the RIS contained open-ended items (e.g., What factors do you believe slow your progress toward completing your dissertation?).

Procedure. At the time of data collection, informed consent forms and a RIS questionnaire were distributed to all participants, followed by the approval of the Institutional Review Board (IRB). Informed consent forms were collected with the completed questionnaires. All precautions were taken by the researchers in the study not to reveal the identities of the respondents. Any identifying information was removed from the dataset.

\subsection{Data Analysis (Step 9)}

Mixed analysis. A sequential mixed analysis (SMA; Onwuegbuzie \& Teddlie, 2003; Tashakkori \& Teddlie, 1998) was used to analyze the data. The SMA comprised six stages that involved descriptive, exploratory, or confirmatory analyses. Specifically, the data were analyzed via a quantitative analysis (i.e., independent samples $t$ test), followed by a qualitative analysis (i.e., a constant comparison analysis), followed by a quantitative analysis of the qualitative data. Each stage of data analysis will be described in the following sections.

Stage 1: Descriptive analysis. In the first stage, an inferential analysis was conducted to compare GPA scores across gender. Specifically, an independent samples $t$ test was used to examine the difference in GPA between the female and male doctoral students.

Stage 2: Exploratory analysis. In the second stage, an exploratory analysis was undertaken to examine the doctoral students' perceptions of barriers that slow the progress toward completing a doctoral dissertation. The researchers conducted a constant comparison analysis to generate a set of themes from the data (Glaser, 1965; Glaser \& Strauss, 1967). According to Glaser (1965), the purpose of constant comparison analysis is to generate a theory by using a more delineated and thorough process. Multiple rounds of reading narratives spurred the generation of descriptive codes and, subsequently, themes that indicated that saturation was reached (Flick, 1998; Lincoln \& Guba, 1985; Morse, 1995; Strauss \& Corbin, 1990). 
The researchers progressed through the three stages of constant comparison analysis: (a) open coding, (b) axial coding, and (c) selective coding (Glaser, 1965; Glaser \& Strauss, 1967). Each researcher created and assigned multiple different codes to the data. These coding choices were determined by each researcher's interpretation of the data (Carley, 1993). After each researcher independently generated codes through numerous rounds of coding, the researchers paired into two groups and developed themes based on generated codes. Then, all researchers discussed the themes that were developed between the two groups. For the purpose of inter-coder agreement between these two groups, inter-coder reliability was calculated using ReCal (Freelon, 2010). Krippendorf's Alpha was .83, indicating good agreement, 83\% inter-coder reliability (Altman, 1991). A peer debriefing also was conducted in order to legitimize the data interpretations (Onwuegbuzie, Leech, \& Collins, 2008). For this study, the remaining researcher who did not originally code the data served as the peer debriefer. In order to examine the audit trail (Lincoln \& Guba, 1985), the peer debriefer had two goals: (a) to ensure that all interpretations stemmed directly from the data and (b) to ensure that all researchers reached agreement on the themes that were identified.

Stage 3: Exploratory analysis. In the third stage, each theme that was identified from the constant comparison analysis was quantitized (Tashakkori \& Teddlie, 1998). This technique allowed the researchers to determine the hierarchical structure of the emergent themes (Onwuegbuzie \& Teddlie, 2003). Specifically, in order to determine the prevalence rate of each barrier theme, frequencies were computed by assigning either a score of " 1 " (if a doctoral student's response contained a characteristic that was assigned to the particular theme) or a score of " 0 " (otherwise). This dichotomization led to the development of an inter-respondent matrix of themes (i.e., student $x$ theme matrix) (Onwuegbuzie, 2003a; Onwuegbuzie \& Teddlie, 2003), which consisted only of 0 s and $1 \mathrm{~s}$. By calculating the frequency of each theme from the inter-respondent matrix, percentages were computed to determine the prevalence rate of each theme (Research Question 3). These frequencies served as effect sizes (Onwuegbuzie \& Teddlie, 2003).

Stage 4: Exploratory analysis. In the fourth stage, an additional exploratory analysis was conducted by using the inter-respondent matrix of themes that was produced during the previous stage to conduct a principal component analysis (Onwuegbuzie, 2003a). Specifically, an orthogonal (i.e., varimax) rotation was utilized. Three techniques were used to determine the number of factors to retain (Kieffer, 1999): (a) the eigenvalue-greater-than-one rule (i.e., K1) (Kaiser, 1958), (b) the scree test that represents a plot of the eigenvalues against the factors in descending order (Cattell, 1966; Zwick \& Velicer, 1982, 1986), and (c) a parallel analysis (Thompson, 2004; Zwick \& Velicer, 1982, 1986). These extracted factors represented meta-themes (Onwuegbuzie, 2003a) such that each meta-theme contained one or more of the emergent reason themes. As recommended by Onwuegbuzie (2003a), the trace, or proportion of variance explained by each factor after rotation, served as an effect size index for each meta-theme. By determining the hierarchical relationship among the barrier themes (Research Question 5), the verification component of categorization was empirical, technical, and rational (Constas, 1992). The meta-themes extracted via the principal components analysis themselves were quantitized to dichotomous data (i.e., "0" vs. " 1 "), 
yielding an inter-respondent matrix of meta-themes.

Stage 5 and Stage 6: Confirmative analysis. In the fifth stage, a chi-square automatic interaction detection (CHAID; Kass, 1980) analysis was used to examine the relationships between the two demographic variables (i.e., gender, GPA) and the six barrier themes (Dillon \& Kumar, 1994). In the sixth stage, a latent class analysis was conducted to determine the smallest number of clusters (i.e., latent classes) that explains all the relationships among the emergent barrier themes. The latent class analysis was conducted under the assumption that participants could be classified into a small number of distinct clusters known as latent classes depending on their profiles of the barrier themes, such that each participant belonged to only one cluster.

\section{Results (Step 9)}

\subsection{Stage 1: Descriptive Findings}

Because GPA scores for males and for females were not normally distributed, using Onwuegbuzie and Daniel's (2002) criteria of \pm 3 for standardized skewness (i.e., skewness coefficient divided by its standard error) and standardized kurtosis (i.e., kurtosis coefficient divided by its standard error) coefficients (see Table 1), a nonparametric (i.e., Mann-Whitney's $U$ ) independent samples $t$ test was used to assess gender differences in GPA scores. The result revealed a statistically significant gender difference in GPA, $U=3579.50, p<.05$. The Cohen's $d$ effect size associated with this difference was 0.35 . Using Cohen's (1988) criteria, this finding represented a small effect size. Present in Table 2 are the descriptive statistics for GPA scores for male doctoral students and for female doctoral students.

Table 1. Stage 1: Standardized skewness coefficients and standardized kurtosis coefficients for GPA scores by gender ${ }^{1}$

\begin{tabular}{|l|l|l|}
\hline Gender & Standardized Skewness Coefficient & Standardized Kurtosis Coefficient \\
\hline Males & 4.43 & 4.48 \\
\hline Females & -30.38 & 133.87 \\
\hline
\end{tabular}

Note. 1: According to Onwuegbuzie and Daniel (2002), variables for which either the standardized skewness coefficient (i.e., skewness coefficient divided by its standard error) or the standardized kurtosis coefficient (i.e., kurtosis coefficient divided by its standard error), or both, are outside the \pm 3 range suggest extreme departure from normality. Thus, both variables indicated very serious departures from normality. 


\section{IIMacrothink}

Table 2. Stage 1: Means and standard deviations of GPA obtained by males and females

\begin{tabular}{|l|l|l|l|}
\hline \multirow{2}{*}{ Gender } & \multicolumn{3}{|c|}{ GPA } \\
\cline { 2 - 4 } & $n$ & $M$ & $S D$ \\
\hline Males & $n$ & 3.78 & 0.19 \\
\hline Females & 74 & 3.78 & 0.42 \\
\hline
\end{tabular}

\subsection{Stage 2 and Stage 3: Exploratory Theme-Related Findings}

The researchers identified codes and themes (Stage 2) by utilizing constant comparison analysis (Glaser, 1965; Glaser \& Strauss, 1967). The following six themes emerged: external obligations, practical/logistical constraints, emotional concerns, challenges to doctoral-level researchers, program structure, and lack of support for completion. Table 3 presents these six themes, along with corresponding significant statements, formulated meaning, and prevalence rate (Stage 3) of each theme (Onwuegbuzie, 2003a; Onwuegbuzie \& Teddlie, 2003). The theme, external obligations was the most prevalent theme $(36 \%)$, followed by challenges to doctoral-level researchers (34\%), practical/logistical constraints (23\%), emotional concerns (15\%), and program structure (9\%). The lack of support for completion theme was the least prevalent theme, with a prevalence rate of 8\%. Using Cohen's (1988, pp. 180-183) non-linear arcsine transformation and Cohen's (1988) $d$ criteria led to cut-points of $1 \%$ endorsement as representing a small effect size, $7 \%$ endorsement as representing a medium effect size, and 16\% endorsement as representing a large effect size. Thus, four themes (i.e., external obligations, challenges to doctoral-level researchers, practical/logistical constraints, emotional concerns) represented a large effect size, whereas the remaining two themes (i.e., program structure, lack of support for completion) represented a moderate effect size. 
Table 3. Stage 2 and Stage 3 analyses: Themes, frequencies, formulated meanings, and selected examples of statements

\begin{tabular}{|c|c|c|c|}
\hline Themes & Frequency & Formulated Meaning & Sample Participant Statements \\
\hline $\begin{array}{l}\text { External } \\
\text { obligations }\end{array}$ & $36 \%$ & $\begin{array}{l}\text { Family, job, social, } \\
\text { medical obligation }\end{array}$ & $\begin{array}{l}\text { My parents are ill, and my children are young. Both } \\
\text { require much of my time! Working full time may slow } \\
\text { down my progress. }\end{array}$ \\
\hline $\begin{array}{l}\text { Challenges to } \\
\text { doctoral-level } \\
\text { researchers }\end{array}$ & $34 \%$ & $\begin{array}{l}\text { Concerns and unforeseen } \\
\text { issues in the research } \\
\text { process }\end{array}$ & $\begin{array}{l}\text { Writing skills, find appropriate subjects, validity and } \\
\text { reliability of the research instrument. } \\
\text { Yes. Finding interview subjects willing to speak } \\
\text { openly. } \\
\text { Red tape from IRB. }\end{array}$ \\
\hline $\begin{array}{l}\text { Practical/ } \\
\text { Logistical } \\
\text { Constraints }\end{array}$ & $23 \%$ & $\begin{array}{l}\text { Time/financial/distance } \\
\text { issues }\end{array}$ & $\begin{array}{l}\text { Distance? I will be applying for jobs at GPC for } \\
\text { Sept. } 04 . \\
\text { Time management/Financial constraints. }\end{array}$ \\
\hline $\begin{array}{l}\text { Emotional } \\
\text { concerns }\end{array}$ & $15 \%$ & $\begin{array}{l}\text { Anxiety, lack of } \\
\text { motivation/interest, } \\
\text { burn-out, procrastination }\end{array}$ & $\begin{array}{l}\text { Anxiety regarding design, methodology, and } \\
\text { anything even remotely related to statistics. } \\
\text { My own motivation - perhaps if I am burnt out by } \\
\text { that time. }\end{array}$ \\
\hline $\begin{array}{l}\text { Program } \\
\text { structure }\end{array}$ & $9 \%$ & $\begin{array}{l}\text { Program sequence, } \\
\text { taking multiple courses, } \\
\text { taking comprehension } \\
\text { exams, inflexibility }\end{array}$ & $\begin{array}{l}\text { Yes, the school psychology program is extremely } \\
\text { time consuming \& it is extremely challenging to find } \\
\text { extra time to do outside projects (thesis \& } \\
\text { Dissertation). } \\
\text { The policies may change midstream and throw me } \\
\text { "off course" on topic. }\end{array}$ \\
\hline $\begin{array}{l}\text { Lack of } \\
\text { support for } \\
\text { completion }\end{array}$ & $8 \%$ & $\begin{array}{l}\text { Lack of connectedness/ } \\
\text { resources/guidance from } \\
\text { faculty }\end{array}$ & $\begin{array}{l}\text { Lack of guidance from major professor. } \\
\text { Assembling committee for review and input and } \\
\text { feedback. }\end{array}$ \\
\hline
\end{tabular}

\subsection{Stage 4: Exploratory Meta-Themes Findings}

A principal components analysis (PCA) was used to determine the number of factors underlying the six emergent themes. The K1 rule (Kaiser, 1958), scree test (Zwick \& Velicer, 1986), and parallel analysis (see Table 4; Zwick \& Velicer, 1986) consistently suggested the retention of three factors, which are presented in Table 5. A cut-off correlation of 0.3 recommended by Lambert and Durand (1975) was used as an acceptable minimum values for pattern/structure coefficients. 
Table 4. Stage 4 analysis: Results from the parallel analysis

\begin{tabular}{|l|l|l|l|}
\hline Component & Eigenvalue from Varimax Rotation & Eigenvalue from the Parallel Analysis & Decision \\
\hline 1 & 1.547 & 1.393230 & Accepted \\
\hline 2 & 1.264 & 1.200637 & Accepted \\
\hline 3 & 1.099 & 1.093766 & Accepted \\
\hline 4 & .975 & 1.002618 & Rejected \\
\hline 5 & .904 & .928491 & Rejected \\
\hline 6 & .211 & .832714 & Rejected \\
\hline
\end{tabular}

Table 5. Stage 4 analysis: Factor pattern/structure from principal coefficients from principal component analysis (Varimax): Three-factor solution

\begin{tabular}{|l|l|l|l|l|}
\hline Factor Coefficients $^{1}$ & \multicolumn{4}{|l|}{} \\
\hline Variable & 1 & 2 & 3 & Communality Coefficient \\
\hline External Obligations & -.931 & -.154 & -.058 & .89 \\
\hline Challenges to Doctoral-level Researchers & $\mathbf{. 7 1 4}$ & $\mathbf{- . 3 9 7}$ & -.100 & .68 \\
\hline Practical/Logistical Constraints & .034 & $\mathbf{. 7 4 3}$ & .152 & .58 \\
\hline Lack of Support for Completion & .160 & $\mathbf{- . 6 0 2}$ & $\mathbf{. 3 3 9}$ & .50 \\
\hline Program Structure & .157 & .119 & $\mathbf{- . 8 4 4}$ & .75 \\
\hline Emotional concerns & .295 & .375 & $\mathbf{. 5 3 1}$ & .51 \\
\hline Trace & 1.51 & 1.25 & 1.14 & 3.91 \\
\hline \% of Variance Explained & 25.24 & 20.84 & 19.06 & \\
\hline
\end{tabular}

Note. ${ }^{1}$ Coefficients in bold represent pattern coefficients with the largest effect size within each theme using a cut-off value of 0.3 recommended by Lambert and Durand (1975).

The PCA yielded the following three meta-themes: dissociation (containing the external obligations and challenges to doctoral-level researchers themes), external/internal barriers 
(containing the practical/logistical constraints and lack of support for completion themes), and institutional/personal barriers (containing the emotional concerns and program structure themes). It should be noted that in addition to having a pattern/structure coefficient with a large effect size on the dissociation meta-theme, challenges to doctoral-level researchers also had a significant but smaller pattern/structure coefficient on the external/internal barriers meta-theme (i.e., cross-loading). Also, in addition to having a pattern/structure coefficient with a large effect size on the external/internal barriers meta-theme, lack of support for completion also had a significant but smaller pattern/structure coefficient on the institutional/personal barriers meta-theme.

Table 6 presents the meta-themes, together with relevant themes and formulating meanings for each meta-theme. External obligations and challenges to doctoral-level researchers within the dissociation meta-theme were negatively related, indicating that students who cited external obligations were less likely to cite challenges to doctoral-level researchers as barriers to slow down the dissertation process, which implied that students who had external obligations were likely to be dissociated with academic experiences. Within the external/internal barriers meta-theme, the practical/logistical constraints theme was negatively related to the support for completion theme. The practical/logistical constraints theme was identified as an external barrier, whereas the support for completion theme was identified as an internal barrier. Within the institutional/personal barriers meta-theme, the program structure theme was negatively related to the emotional concerns theme, indicating that students who cited program structure were less likely to cite emotional concerns. The theme program structure was identified as an institutional barrier, whereas the emotional concerns theme was identified as a personal barrier.

Table 6. Stage 4 analysis: Description of meta-themes emerging from principal component analysis

\begin{tabular}{|l|l|l|}
\hline Meta-themes & Themes & Descriptions \\
\hline Disassociation & $\begin{array}{l}\text { External Obligations } \\
\text { Challenges to Doctoral-level Researchers }\end{array}$ & $\begin{array}{l}\text { An integrated life/identity becomes } \\
\text { separated due to multiple roles or } \\
\text { obligations }\end{array}$ \\
\hline $\begin{array}{l}\text { External/internal } \\
\text { barriers }\end{array}$ & $\begin{array}{l}\text { Practical/Logistical Constraints } \\
\text { Challenges to Doctoral-level Researchers } \\
\text { Lack of Support for Completion }\end{array}$ & $\begin{array}{l}\text { Alienation/isolation from the } \\
\text { academic experiences in the doctoral } \\
\text { program due to practical/logistical } \\
\text { constraints }\end{array}$ \\
\hline $\begin{array}{l}\text { Developmental } \\
\text { issues within the } \\
\text { doctoral programs }\end{array}$ & $\begin{array}{l}\text { Lack of Support for Completion } \\
\text { Program Structure }\end{array}$ & $\begin{array}{l}\text { Institutional barriers and emerged } \\
\text { emotions within the developmental } \\
\text { process in the doctoral programs }\end{array}$ \\
\hline
\end{tabular}




\section{Macrothink}

\subsection{Stage 5: Chi-Square Automatic Interaction Detection}

The CHAID analysis revealed that only external/internal barriers discriminated males and females. Figure 2 graphically depicts the decision tree that emerged from the CHAID analysis: whereas $68.4 \%$ of males cited external obligations, only $51.9 \%$ of females cited external obligations, which represented a statistically significant difference with a moderate effect size (Cramer's $V=.27$ ).

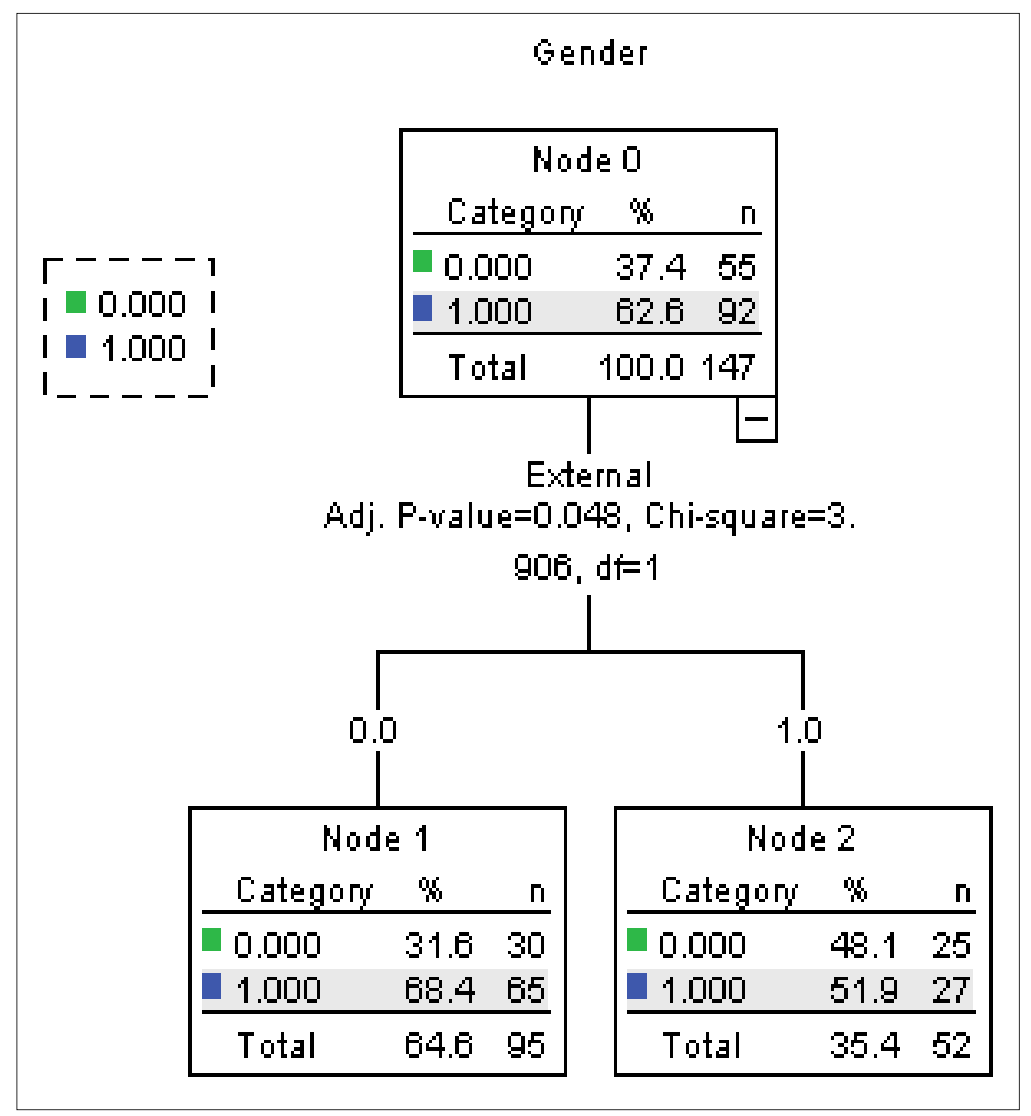

Figure 2. Stage 5 findings: Visual representation from the CHAID analysis of the one theme that discriminated males and females

\subsection{Stage 6: Latent Class Analysis Findings}

The latent class analysis revealed a four-cluster solution $\left(L^{2}=46.66, d f=36, p=.11\right)$. Figure 3 displays these four distinct groups of participants. It can be seen from Figure 3 that Cluster 1 (comprising $35.8 \%$ of participants) was relatively high only with respect to the theme challenges to doctoral-level researchers but relatively low with respect to the five other themes. Cluster 2 (comprising $31.6 \%$ of participants) was high on external obligations but relatively low with respect to the five other themes. Cluster 3 (comprising $20.3 \%$ of participants) was high on practical/logistical constraints but relatively low with respect to the five other themes. Finally, Cluster 4 (comprising $12.3 \%$ of participants) was high on 
emotional concerns but relatively low with respect to the five other themes.

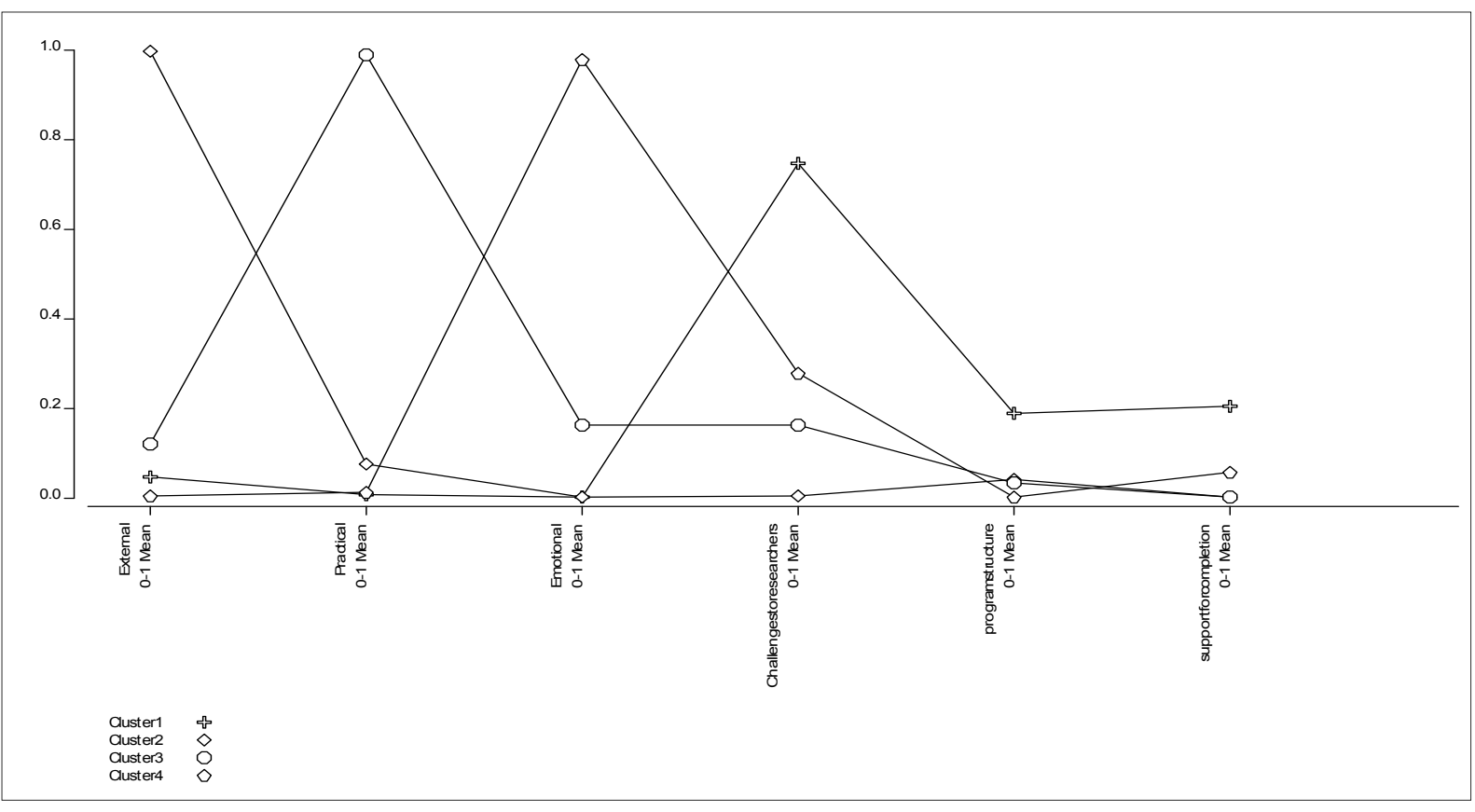

Figure 3. Stage 6 findings: Profiles of the participants with respect to the six barrier themes

Further, Figure 3 indicates that the following four themes statistically significantly discriminated the four clusters: external obligations (Wald $=11.34, p=.001, R^{2}=83.14 \%$ ), practical/logistical constraints (Wald $=8.76, p=.0033, R^{2}=83.91 \%$ ), emotional concerns (Wald $=7.79, p<.05, R^{2}=76.13 \%$ ), and challenges to doctoral-level researchers $($ Wald $=$ $25.45, p<.0001, R^{2}=45.40 \%$ ). Conversely, the remaining two themes did not statistically significantly discriminate the four clusters: program structure (Wald $=6.56, p=.087, R^{2}=$ $7.26 \%$ ) and lack of support for completion (Wald $=3.16, p=.37, R^{2}=12.00 \%$ ). The $R^{2}$ values revealed that practical/logistical constraints, external obligations, and emotional concerns, respectively, had the most variance explained by the four-cluster model.

\section{Discussion}

\subsection{Legitimation of the Findings (Step 10)}

Based on threats to internal and external validity delineated by Onwuegbuzie (2003b), the possible threats to internal and external validity were identified at the data collection, data analysis, and data interpretation stages of the quantitative research phase. Additionally, with regard to the qualitative research phase, the possible threats to internal and external credibility of the findings (Onwuegbuzie \& Leech, 2007) were identified. Specifically, two potential threats to external validity were identified at the research/design, data collection, or data analysis stages of the quantitative research phase of the study: (a) ecological/temporal validity and (b) population validity (Onwuegbuzie, 2003b). With regard to the qualitative 
research phase of the study, three potential threats to internal and external credibility of the findings were identified: (a) descriptive validity, (b) researcher bias, and (c) interpretive validity.

Validity of findings from the quantitative phase. Ecological/temporal validity and population validity are related to the generalizability of the findings (Onwuegbuzie, 2003b). Data were purposively gathered from a single university in a singular region of the United States. Thus, it is not clear the extent to which the present findings generalize beyond the sample to doctoral students from other institutions in other regions of the United States and beyond. However, the fact that this study involved more than 200 participants that represented adequate statistical power (i.e., .97) is noteworthy. Further, it should be noted that data were drawn from more than 30 different degree specialty areas among students pursuing doctoral degrees representing the field of education, thereby increasing the generalizability of the findings across the field of education - at least at the institution where the study took place.

Legitimation of findings from the qualitative phase. Descriptive validity represents the researcher's factual accuracy of the account (Maxwell, 1992). However, this threat likely was reduced by the fact that several of the researchers are doctoral students themselves and thus had an emic perspective. Researcher bias was a potential threat in this study due to the researchers serving as instruments of the qualitative data analysis when deriving codes and themes. Because the researchers had various philosophies and lived experiences, the existence of bias might have unduly influenced the decisions of design, data collection, and analysis of this study. Thoroughness and rigor were carefully considered during the analysis of qualitative data. Particular attention was paid to the threat of researcher bias. Several steps were taken in order to attempt to minimize researcher bias. In particular, the researchers participated in two debriefing sessions - one debriefing session after the initial coding of the data and an additional debriefing session following the discussion, agreement, and finalizing of coding procedures. The following debriefing questions were adapted from Onwuegbuzie et al. (2008): (a) How comfortable were you with the participants?; (b) What findings surprised you?; (c) What barriers were expressed?; (d) What ethical issues did you encounter?; (e) What dilemmas did you encounter during the study?; (f) How did you handle the dilemma?; and (g) Is there anything else that you would like to add or share? Interpretive validity, which is the extent to which the researcher's interpretation of the account is in alignment with the perspectives of the individuals being studied (Maxwell, 1992), posed as a threat to the findings. However, as was the case for descriptive validity, the emic perspective provided by some of the researchers likely minimized this threat.

Legitimation of findings from the mixed research phase. Onwuegbuzie and Johnson (2006) identified nine legitimation types that are pertinent to mixed research. Each of these legitimation types is defined in Table 7, coupled with an explanation of how they were addressed in the current study. It can be seen that nine threats were addressed to some degree. Nevertheless, despite the extremely rigorous nature of the mixed research design, replications of this study are needed to assess the generalizability of the present findings. 
Table 7. Typology of mixed methods legitimation types and approaches used to minimize them

\begin{tabular}{|c|c|c|}
\hline Legitimation Type & Description & How Legitimation Type was Enhanced \\
\hline Sample Integration & $\begin{array}{l}\text { The extent to which the relationship } \\
\text { between the quantitative and qualitative } \\
\text { sampling designs yields quality } \\
\text { meta-inferences. }\end{array}$ & $\begin{array}{l}\text { Collecting both qualitative and quantitative data on the } \\
\text { same group of doctoral student participants }\end{array}$ \\
\hline Inside-Outside & $\begin{array}{l}\text { The extent to which the researcher } \\
\text { accurately presents and appropriately } \\
\text { utilizes the insider's view and the observer's } \\
\text { views for purposes such as description and } \\
\text { explanation. }\end{array}$ & $\begin{array}{l}\text { Capturing the participants' quantitative and qualitative } \\
\text { data (i.e., emic view) and including doctoral students } \\
\text { (i.e., emic view), a recently graduated doctoral student } \\
\text { (i.e., emic and etic view), and doctoral-level } \\
\text { instructor/professor (i.e., etic view) on the research } \\
\text { team }\end{array}$ \\
\hline $\begin{array}{l}\text { Weakness } \\
\text { Minimization }\end{array}$ & $\begin{array}{l}\text { The extent to which the weakness from one } \\
\text { approach is compensated by the strengths } \\
\text { from the other approach. }\end{array}$ & $\begin{array}{l}\text { Combining descriptive precision (i.e., stemming from } \\
\text { qualitative analyses) with empirical precision (i.e., } \\
\text { stemming from quantitative analyses) }\end{array}$ \\
\hline Sequential & $\begin{array}{l}\text { The extent to which one has minimized the } \\
\text { potential problem wherein the } \\
\text { meta-inferences could be affected by } \\
\text { reversing the sequence of the quantitative } \\
\text { and qualitative phases. }\end{array}$ & $\begin{array}{l}\text { Collecting quantitative and qualitative data } \\
\text { simultaneously (i.e., concurrently) }\end{array}$ \\
\hline Conversion & $\begin{array}{l}\text { The extent to which the quantitizing or } \\
\text { qualitizing yields quality meta-inferences. }\end{array}$ & $\begin{array}{l}\text { Obtaining verification of quantitizing of themes via } \\
\text { inter-coder agreement, debriefing, and analysis of audit } \\
\text { trail }\end{array}$ \\
\hline $\begin{array}{l}\text { Paradigmatic } \\
\text { mixing }\end{array}$ & $\begin{array}{l}\text { The extent to which the researcher's } \\
\text { epistemological, ontological, axiological, } \\
\text { methodological, and rhetorical beliefs that } \\
\text { underlie the quantitative and qualitative } \\
\text { approaches are successfully (a) combined or } \\
\text { (b) blended into a usable package. }\end{array}$ & $\begin{array}{l}\text { Using a fully mixed research design (Leech \& } \\
\text { Onwuegbuzie, 2009), as well as by undergoing all } \\
\text { major steps of the mixed research process }\end{array}$ \\
\hline Commensurability & $\begin{array}{l}\text { The extent to which the meta-inferences } \\
\text { made reflect a mixed worldview based on } \\
\text { the cognitive process of Gestalt switching } \\
\text { and integration. }\end{array}$ & $\begin{array}{l}\text { Using a team of researchers that was diverse with } \\
\text { respect to research training, research experience, } \\
\text { research philosophy, college teaching experience (e.g., } \\
\text { adjunct professor, full professor), and discipline (e.g., } \\
\text { literacy, educational leadership, higher education, } \\
\text { educational psychology, research methodology) }\end{array}$ \\
\hline Multiple Validities & $\begin{array}{l}\text { The extent to which addressing legitimation } \\
\text { of the quantitative and qualitative } \\
\text { components of the study result from the use } \\
\text { of quantitative, qualitative, and mixed } \\
\text { validity types, yielding high quality } \\
\text { meta-inferences. }\end{array}$ & $\begin{array}{l}\text { Using techniques (e.g., inter-coder agreement, } \\
\text { debriefing) that addressed as many threats to the } \\
\text { legitimation of both the qualitative and quantitative } \\
\text { findings as possible }\end{array}$ \\
\hline Political & $\begin{array}{l}\text { The extent to which the consumers of mixed } \\
\text { research value the meta-inferences } \\
\text { stemming from both the quantitative and } \\
\text { qualitative components of a study. }\end{array}$ & Using rigorous qualitative and quantitative techniques \\
\hline
\end{tabular}

Note. This table was adapted from Onwuegbuzie and Johnson (2006). Reprinted with kind permission of the Mid-South Educational Research Association and the Editors of Research in the Schools. 


\subsection{Interpretation of the Findings (Step 11)}

In our quantitative analysis, the gender difference in GPA was statistically significant with a small effect size. This finding indicates that, to a small degree, female doctoral students attained higher levels of academic performance than did their male counterparts, which was consistent with findings in the previous studies (Berg \& Ferber, 1983; Girves \& Wemmerus, 1988). With respect to the qualitative analysis, the responses of the doctoral students indicated various challenges that they experienced. Not only did they experience struggles within the program (i.e., program structure, lack of support for completion, challenges to doctoral level researchers) but also in balancing the program with their daily lives (i.e., external obligations, practical/logistical constraints). This is in line with previous findings about non-academic challenges that doctoral students face (Maher et al., 2004; Moyer et al., 1999). Six themes emerged, illustrating students' perceived barriers in multiple directions in developing their professional identities. The two most prevalent themes, external obligations and challenges to doctoral-level researchers, were distinct barriers that the students experienced. We identified external obligations as the non-academic responsibilities/obligations imposed (e.g., family obligations, employment obligations, social obligations, medical obligations). Within Weidman et al.'s (2001) Graduate Socialization Framework, which predicts that personal communities (e.g., family, employment) influence doctoral student completion, this finding indicates that these external obligations might be the stressors that cause students to slow student progress, to reduce student success in coursework and their research, and, ultimately, to increase student attrition (Barnett, 2009; Boes, Ullery, Millner, \& Cobia, 1999). Boes et al. (1999) claimed that part-time doctoral students might have difficulty in fulfilling doctoral requirements and developing a professional identity due to their obligations to work, family, and friends, compared to full-time doctoral students. For part-time doctoral students, coping strategies were utilized that included creating a support structure of friends, family, peers, and employees and maintaining ongoing communication with advisors to meet the academic deadlines and share their financial obligations (Boes et al., 1999).

Additionally, challenges to individual researchers included concerns and unforeseen issues related to research methodologies and writing. Some doctoral students might perceive an inconceivably high pressure to acquire research knowledge and skills that are needed for their professional practices. Although many doctoral programs build research projects into their coursework, it is likely that many of these students still suffer from anxiety relating to conducting research studies (e.g., research anxiety; statistics anxiety; library anxiety, writing anxiety; see for e.g., Onwuegbuzie, 1997; Onwuegbuzie \& Wilson, 2003). Unfortunately, this research anxiety prevents at least some doctoral students from completing their doctoral programs by (a) hindering them from gaining knowledge and skills maximally in research methodology courses (e.g., quantitative research courses, qualitative research courses, mixed research courses); and/or (b) reducing their levels of confidence in conducting/completing their dissertation research studies (Onwuegbuzie, 1997).

Our mixed analysis revealed three meta-themes underlying the original six themes. The meta-theme dissociation, that contained the two themes of external obligations and 
challenges to doctoral level researchers, demonstrated the compartmentalized life of doctoral students with multiple roles assigned simultaneously. These multiple roles might keep doctoral students from concentrating on fulfilling the requirements for their academic or professional development. Additionally, the meta-theme external/internal barriers, associated with three themes (i.e., practical/logistical constraints, challenges to doctoral level researchers and lack of support for completion), implied that time/finance/distance issues might restrict doctoral students from not only being engaged in their own research projects but also interacting with their professors and peers, which might be essential for the academic and social integration of doctoral students (Tinto, 1993). Finally, the meta-theme, institutional/personal barriers, associated with three themes (i.e., program structure, lack of support for completion, and emotional concerns) indicated that doctoral students might identify different barriers depending on their stage (e.g., coursework, candidacy, and dissertation) within their programs, consistent with Tinto's (1993) doctoral persistent theory. Students who cited program structure (e.g., course sequence, flexibility of course schedule) still might not reach the candidacy or dissertation stage, whereas students who cited lack of support/resources and emotional concerns (e.g., burn-out, lack of motivation) were possibly at either candidacy or dissertation stage wherein the tie with faculty members or peers might be loosened on the daily basis.

Interestingly, our quantitative finding showed that male doctoral students were more likely to cite external obligations than were female doctoral students. This finding suggests that male students in doctoral programs might undergo intensified external obligations compared to female doctoral students. Some of previous studies have focused on external obligations imposed on female doctoral students such as childcare responsibilities, indicating that these external obligations influence their completion negatively (e.g., Maher et al., 2004; Manfield et al., 2010). However, there has been little research attention paid to male doctoral students. Berg and Ferber (1983) found that male graduate students, especially in predominantly feminized fields like education, were less likely to receive financial support (e.g., fellowship/assistantship) and less likely to be satisfied with practicum supervision. To lessen external obligations of male doctoral students and enhance their completion rates, further studies and practices are needed.

\subsection{Writing the Mixed Research Report (Step 12) and Re-formulating the Mixed Research Questions (Step 13)}

In writing our research report, we have provided evidence that doctoral students have barriers that slow down their progress toward completing their doctoral dissertations that are complex and multifaceted. Unfortunately, because doctoral students receive relatively little attention with regard to barriers that they face, replication of our study is paramount. Moreover, based on the current findings, future scholars conducting research on this topic might consider addressing the following questions: (a) What barriers, if any, do doctoral student at each stage (i.e., coursework, candidacy, dissertation) perceive?; and (b) How does gender discriminate these barriers? 


\subsection{Suggestions for Educational Leaders in Higher Education}

The current investigation indicates that doctoral students experience numerous types of barriers in completing their doctoral programs. When students enter their doctoral programs, they encounter new responsibilities as students, such as attending classes, acquiring new research skills and knowledge to be a proficient scholar, and communicating with peers and professors. These additional roles might be in conflict with their existing responsibilities. When they attempt to improve their challenging situations by seeking a support system, it leads to both professional and personal development (Sanford, 1966). However, if they encounter too many challenges but no support, they might drop out from their degree programs (Gardner, 2009). For example, external obligations and practical/logistical limitations might hamper doctoral students from being actively engaged in their research studies and interacting with their peers and faculty. This finding implies that a better support system should be provided in order to mitigate these external challenges that doctoral students face and foster their professional as well as personal development (Gardner, 2009). Correspondingly, Byers et al. (2014) have suggested several strategies for helping students negotiate doctoral completion, such as offering flexible classes with multiple sections of a class or online class components, providing childcare for events and seminars, increasing scholarships, and training faculty to be responsive to students issues.

Furthermore, it might be tremendously significant for educational leaders to recognize possible challenges at each stage of their students' doctoral programs (Gardner, 2009; Tinto, 1993). In the current study, challenges to doctoral-level researchers and lack of support for completion were indicated as barriers in relation to acquiring/demonstrating research competencies as an emergent scholar. These challenges might be intensified when they reach their candidacy/dissertation phases (Gardner, 2009). To minimize these challenges, possible actions might be taken: (a) creating a writing group,(b) building mentoring relationships with professors and/or peers, and (c) building support relationships with individual doctoral students (Gardner, 2009). Lastly, different strategies might need to be applied as a function of gender because, according to our finding, male and female doctoral students might perceive these barriers differently. In establishing a support system within the departments, it should be assured that male students, especially those in the field of a high proportion of female faculty, have equal opportunities in obtaining scholarships, financial assistantship, or rewards (Berg \& Ferber, 1983).

\section{Conclusion}

In this study, the researchers have attempted to identify perceived barriers of doctoral students and to discover relationships among these barriers with the hope of identifying ways in which institutions can aid students in mitigating and overcoming these challenges. The six themes reflected various barriers that were perceived by doctoral students such as institutional, personal, external, and internal barriers. Additionally, the three meta-themes revealed how the underlying themes were related with one and another. These themes and meta-themes provide compelling evidence that these barriers are multi-dimensional in nature.

There is no generalized model to explain doctoral student persistence because of its 
complexity that is associated with various individual characteristics (e.g., aptitude, aspiration, family/employment /financial status, family background) and institutional culture/support level (Tinto, 1993). To improve doctoral completion, both doctoral students and individuals within institutions who are responsible for their educational welfare (e.g., instructors, advisors/supervisors, mentors, curriculum developers) should be aware of possible challenges at each stage of doctoral programs and develop a support system. In terms of this support, professors or advisors could have a crucial role as mediators between their doctoral students and the students' personal communities by working to connect with the students beyond their academic roles (e.g., developing more personal relationships with students, relating their own barriers and challenges in academia to the students as well as the strategies used to overcome these challenges) in order to help graduate students both develop their professional identities and obtain an effective balance between their professional and personal lives.

\section{References}

Altman, D. G. (1991). Practical statistics for medical research. London, England: Chapman and Hall.

Attiyeh, G. M. (1999). Determinants of persistence of graduate students in Ph.D. programs (GRE Board Research Report No. 95-18R). Princeton, NJ: Educational Testing Service.

Bair, C. R., \& Haworth, J. G. (2005). Doctoral student attrition and persistence: A meta-synthesis of research. Higher Education: Handbook of Theory and Research, 19, 481-534. http://dx.doi.org/10.1007/1-4020-2456-8_11

Barnett, D. L. (2009). Experiences influencing degree completion articulated by doctoral students in education administration (Doctoral dissertation). Retrieved from http://udini.proquest.com/view/experiences-influencing-degree-goid:304564777/

Berg, H. M., \& Ferber, M. A. (1983). Men and women graduate students: Who succeeds and why? Journal of Higher Education, 54, 629-648. http://dx.doi.org/10.2307/1981934

Boes, S. R., Ullery, E. K., Millner, V. S., \& Cobia, D. C. (1999). Meeting the challenges of completing a counseling doctoral program. Journal of Humanistic Education and Development, 37, 130-144. http://dx.doi.org/10.1002/j.2164-4683.1999.tb00415.x

Bowen, W., \& Rudenstine, N. (1992). In pursuit of the PhD. Princeton, NJ: Princeton University Press. http://dx.doi.org/10.1515/9781400862474

Byers, V. T., Smith, R. N., Hwang, E., Angrove, K. E., Chandler, J. I., Christian, K. M., ... Denham, M. A. (2013). Survival strategies: Doctoral students' perceptions of challenges and coping methods. International Journal of Doctoral Studies, 9, 109-136. Retrieved from http://ijds.org/Volume9/IJDSv9p109-136Byers0384.pdf

Carley, K. (1993). Coding choices for textual analysis: A comparison of content analysis and map analysis. In P. Marsden (Ed.), Sociological methodology (pp. 75-126). Oxford: Blackwell. http://dx.doi.org/10.2307/271007

Cattell, R. B. (1966). The scree test for the number of factors. Multivariate Behavioral 
Research, 1(2), 245-276. http://dx.doi.org/10.1207/s15327906mbr0102_10

Chee, K. H., Pino, N. W., \& Smith, W. L. (2005). Gender differences in the academic ethic and academic achievement. College Student Journal, 39, 604-618.

Cohen, J. (1988). Statistical power analysis for the behavioral sciences (2nd ed.). Hillsdale, NJ: Lawrence Erlbaum.

Collins, K. M. T., Onwuegbuzie, A. J., \& Jiao, Q. G. (2007). A mixed methods investigation of mixed methods sampling designs in social and health science research. Journal of Mixed Methods Research, 1, 267-294. http://dx.doi.org/10.1177/1558689807299526

Collins, K. M. T., Onwuegbuzie, A. J., \& Sutton, I. L. (2006). A model incorporating the rationale and purpose for conducting mixed methods research in special education and beyond. Learning Disabilities: A Contemporary Journal, 4, 67-100.

Constas, M. A. (1992). Qualitative data analysis as a public event: The documentation of category development procedures. American Educational Research Journal, 29, 253-266. http://dx.doi.org/10.3102/00028312029002253

Council of Graduate Schools. (2008). Ph.D. completion and attrition: Analysis of baseline demographic data from the Ph.D. completion project. Washington, DC: Council of Graduate Schools.

Dillon, W. R., \& Kumar, A. (1994). Latent structure and other mixture models in marketing: An integrative survey and overview. In R. Bagozzi (Ed.), Advanced methods of marketing research (pp. 295-351). Cambridge, MA: Blackwell.

Faul, F., Erdfelder, E., Lang, A. G., \& Buchner, A. (2007). G*Power 3: A flexible statistical power analysis program for the social, behavioral, and biomedical sciences. Behavior Research Methods, 39, 175-191. http://dx.doi.org/10.3758/BF03193146

Flick, U. (1998). An introduction to qualitative research: Theory, method and applications. London, England: Sage.

Freelon, D. (2010). ReCal: Intercoder reliability calculation as a web service. International Journal of Internet Science, 5(1), 20-33.

Gardner, S. K. (2009). The development of doctoral students: Phases of challenge and support. ASHE Higher Education Report, 24(6), 1-14. http://dx.doi.org/10.5175/JSWE.2009.200800091

Girves, J. E., \& Wemmerus, V. (1988). Developing models of graduate school degree progress, Journal of Higher Education, 59, 163-189. http://dx.doi.org/10.2307/1981691

Glaser, B. G. (1965). The constant comparative method of qualitative analysis. Social Problems, 12, 436-445. http://dx.doi.org/10.1525/sp.1965.12.4.03a00070

Glaser, B. G., \& Strauss, A. L. (1967). The discovery of grounded theory: Strategies for qualitative research. Chicago, IL: Aldine. 
Golde, C. M. (2000). Should I stay or should I go? Student descriptions of the doctoral attrition process. The Review of Higher Education, 23, 199-227. http://dx.doi.org/10.1353/rhe.2000.0004

Golde, C. M. (2005). The role of the department and discipline in doctoral student attrition: Lessons learned from four departments. The Journal of Higher Education, 76, 669-700. http://dx.doi.org/10.1353/jhe.2005.0039

Greene, J. C., Caracelli, V. J., \& Graham, W. F. (1989). Toward a conceptual framework for mixed-method evaluation designs. Educational Evaluation and Policy Analysis, 11, 255-274. http://dx.doi.org/10.3102/01623737011003255

Johnson, R. B., \& Christensen, L. (2010). Educational research: Quantitative, qualitative, and mixed approaches (4th ed.). Thousand Oaks, CA: Sage.

Kaiser, H. F. (1958). The varimax criterion for analytic rotation in factor analysis. Psychometrika, 23, 187-200. http://dx.doi.org/10.1007/BF02289233

Kass, G. (1980). An exploratory technique for investigating large quantities of categorical data. Applied Statistics, 29, 119-127. http://dx.doi.org/10.2307/2986296

Kieffer, K. M. (1999). An introductory primer on the appropriate use of exploratory and confirmatory factor analysis. Research in the Schools, 6(2), 75-92.

Lambert, Z. V., \& Durand, R. M. (1975). Some precautions in using canonical analysis. Journal of Market Research, XII, 468-475. http://dx.doi.org/10.2307/3151100

Leech, N. L., \& Onwuegbuzie, A. J. (2009). A typology of mixed methods research designs. Quality \& Quantity: International Journal of Methodology, 43, 265-275. http://dx.doi.org/10.1007/s11135-007-9105-3

Lincoln, Y. S., \& Guba, E. G. (1985). Naturalistic inquiry. Beverly Hills, CA: Sage.

Lovitts, B. (2001). Leaving the ivory tower: The causes and consequences of departure from doctoral study. Lanham, MD: Rowman \& Littlefield.

Maher, M. A., Ford, M. E., \& Thompson, C. M. (2004). Degree progress of women doctoral students: Factors that constrain, facilitate, and differentiate. The Review of Higher Education, 27, 385-408. http://dx.doi.org/10.1353/rhe.2004.0003

Malone, B. G., Nelson, J. S., \& Nelson, C. V. (2004). Academic and affective factors contributing to degree completion of doctoral students in educational administration. The Teacher Educator, 40(1), 33-55. http://dx.doi.org/10.1080/08878730409555350

Manfield, K. C., Welton, A., Lee, P. L., \& Young, M. D. (2010). The lived experiences of female educational leadership doctoral students. Journal of Educational Administration, 48, 727-740. http://dx.doi.org/10.1108/09578231011079584

Maxwell, J. A. (1992). Understanding and validity in qualitative research. Harvard Educational Review, 62, 279-299. http://dx.doi.org/10.17763/haer.62.3.8323320856251826 
McAlpine, L., \& Norton, J. (2006). Reframing our approach to doctoral programs: An integrative framework for action and research. Higher Education Research \& Development, 25(1), 3-17. http://dx.doi.org/10.1080/07294360500453012

Morse, J. M. (1995). The significance of saturation. Qualitative Health Research, 5, 147-149. http://dx.doi.org/10.1177/104973239500500201

Moyer, A., Salovey, P., \& Casey-Cannon, S. (1999). Challenges facing female doctoral students and recent graduates. Psychology of Women Quarterly, 23, 607-630. http://dx.doi.org/10.1111/j.1471-6402.1999.tb00384.x

Newman, I., Ridenour, C. S., Newman, C., \& DeMarco, G. M. P. (2003). A typology of research purposes and its relationship to mixed methods. In A. Tashakkori \& C. Teddlie (Eds.), Handbook of mixed methods in social and behavioral research (pp. 167-188). Thousand Oaks, CA: Sage.

Onwuegbuzie, A. J. (1997). Writing a research proposal: The role of library anxiety, statistics anxiety, and composition anxiety. Library and Information Science Research, 19, 5-33. http://dx.doi.org/10.1016/S0740-8188(97)90003-7

Onwuegbuzie, A. J. (2003a). Effect sizes in qualitative research: A prolegomenon. Quality \& Quantity: International Journal of Methodology, 37, 393-409. http://dx.doi.org/10.1023/A:1027379223537

Onwuegbuzie, A. J. (2003b). Expanding the framework of internal and external validity in quantitative research. Research in the Schools, 10(1), 71-90.

Onwuegbuzie, A. J., \& Collins, K. M. T. (2007). A typology of mixed methods sampling designs in social science research. The Qualitative Report, 12, 281-316. Retrieved from http://www.nova.edu/ssss/QR/QR12-2/onwuegbuzie2.pdf

Onwuegbuzie, A. J., \& Daniel, L. G. (2002). Uses and misuses of the correlation coefficient. Research in the Schools, 9(1), 73-90.

Onwuegbuzie, A. J., \& Johnson, R. B. (2006). The validity issue in mixed research. Research in the Schools, 13(1), 48-63.

Onwuegbuzie, A. J., \& Leech, N. L. (2007). Validity and qualitative research: An oxymoron? Quality \& Quantity: International Journal of Methodology, 41, 233-249. http://dx.doi.org/10.1007/s11135-006-9000-3

Onwuegbuzie, A. J., Leech, N. L., \& Collins, K. M. T. (2008). Interviewing the interpretive researcher: A method for addressing the crises of representation, legitimation, and praxis. International Journal of Qualitative Methods, 7(4), 1-17.

Onwuegbuzie, A. J., Slate, J. R., Leech, N. L., \& Collins, K. M. T. (2007). Conducting mixed analyses: A general typology. International Journal of Multiple Research Approaches, 1, 4-17. http://dx.doi.org/10.5172/mra.455.1.1.4

Onwuegbuzie, A. J., \& Teddlie, C. (2003). A framework for analyzing data in mixed methods 
research. In A. Tashakkori \& C. Teddlie (Eds.), Handbook of mixed methods in social and behavioral research (pp. 351-383). Thousand Oaks, CA: Sage.

Onwuegbuzie, A. J., \& Wilson, V. A. (2003). Statistics anxiety: Nature, etiology, antecedents, effects, and treatments: A comprehensive review of the literature. Teaching in Higher Education, 8, 195-209. http://dx.doi.org/10.1080/1356251032000052447

Plano Clark, V. L., \& Badiee, M. (2010). Research questions in mixed methods research. In A. Tashakkori \& C. Teddlie (Eds.), Handbook of mixed methods in social and behavioral research (2nd ed., pp. 275-304). Thousand Oaks, CA: Sage.

Sanford, N. (1966). Self and society. New York, NY: Wiley.

Smith, R. L., Maroney, K., Nelson, K. W., Abel, A. L., \& Abel, H. S. (2006). Doctoral programs: Changing high rates of attrition. The Journal of Humanistic Counseling, Education and Development, 45(1), 17-31. http://dx.doi.org/10.1002/j.2161-1939.2006.tb00002.x

Strauss, A., \& Corbin, J. (1990). Basics of qualitative research: Grounded theory procedures and techniques. Newbury Park, CA: Sage.

Tashakkori, A., \& Teddlie, C. (1998). Mixed methodology: Combining qualitative and quantitative approaches. Thousand Oaks, CA: Sage.

Thompson, B. (2004). Exploratory and confirmatory factor analysis: Understanding concepts and applications. Washington, DC: American Psychological Association.

Tinto, V. (1975). Dropout from higher education: A theoretical synthesis of recent research. Review of Educational Research, 45(1), 98-125. http://dx.doi.org/10.3102/00346543045001089

Tinto, V. (1993). Leaving college: Rethinking the causes and cures of student attrition. Chicago, IL: University of Chicago Press.

Wao, H., \& Onwuegbuzie, A. J. (2011). A mixed research investigation of factors related to time to the doctorate in education. International Journal of Doctoral Studies, 6, 115-134. Retrieved http://ijds.org/Volume6/IJDSv6p115-134Wao320.pdf

Weidman, J. C., Twale, D. J., \& Stein, E. L. (2001). Socialization of graduate and professional students in higher education: A perilous passage? San Francisco, CA: Jossey-Bass.

Zwick, W. R., \& Velicer, W. F. (1982). Factors influencing four rules for determining the number of components to retain. Multivariate Behavioral Research, 17, 253-269. http://dx.doi.org/10.1207/s15327906mbr1702_5

Zwick, W. R., \& Velicer, W. F. (1986). Comparison of five rules for determining the number of components to retain. Psychological Bulletin, 99, 432-442. http://dx.doi.org/10.1037/00332909.99.3.432 


\section{Copyright Disclaimer}

Copyright for this article is retained by the author(s), with first publication rights granted to the journal.

This is an open-access article distributed under the terms and conditions of the Creative Commons Attribution license (http://creativecommons.org/licenses/by/3.0/). 